Autora invitada 


\title{
Enunciación
}

\section{Entrevista a Anne Haas Dyson: "La escritura infantil está entramada con el dibujo, el habla, el canto y el juego"}

\author{
Por Ana Atorresi y Laura Eisner
}

Anne Haas Dyson comenzó a dictar clases a comienzos de la década de 1970, como maestra, y continúa haciéndolo hoy, como profesora, en la Facultad de Educación de la Universidad de Illinois. Hace unos 50 años que investiga, mediante métodos etnográficos, los procesos sociales y culturales de escolarización y literacidad en la infancia; en particular, las culturas infantiles y el rol de la cultura popular en su desarrollo; las prácticas de literacidad extraescolares y escolares en la infancia transcultural actual; las políticas lingüísticas de la escuela y su incidencia en las identidades de los niños y niñas que usan variedades no estándar; el modo en que las sociedades construyen las infancias y la manera en que las niñas y los niños actúan como agentes para edificar infancias propias. Estas investigaciones le han valido a Dyson importantes distinciones y premios. Su amplia obra, que aún no ha sido traducida al español, incluye los siguientes títulos: Child cultures, schooling, and literacy: global perspectives on composing unique lives (2016); ReWRITING the basics: literacy learning in children's cultures (2013); The brothers and sisters learn to write: popular literacies in childhood and school culture (2003); Writing superheroes: contemporary childhood, popular culture, and classroom literacy (1997); Negotiating a permeable curriculum: on literacy, diversity, and the interplay of children's and teacher's worlds (1993); Social worlds of children learning to write in an urban primary school (1993), y Visions of children as language users: research on language and language education in early childhood (1991).

30 de junio de 2020

Anne Haas Dyson started teaching in the early 1970s, first as a schoolteacher and later as a university lecturer, a position she still holds today at the Illinois College of Education. Over the past 50 years she has studied young children's schooling and literacy processes from a social and cultural perspective through an ethnographic approach; in particular, her interests cover childhood cultures and the role of popular culture in their development; school and out-of-school literacy practices in current cross-cultural childhoods; school language policies and their impact on the identities of boys and girls who speak non-standard varieties; institutional expectations on childhood and learning and the emergence of children's agency in constructing their own social worlds. She has received numerous awards throughout her extensive career in recognition to her contribution to the field of childhood literacies. Some of her published works, which have not yet been translated into Spanish, are: Child cultures, schooling, and literacy: global perspectives on composing unique lives (2016); ReWRITING the basics: literacy learning in children's cultures (2013); The brothers and sisters learn to write: popular literacies in childhood and school culture (2003); Writing superheroes: contemporary childhood, popular culture, and classroom literacy (1997); Negotiating a permeable curriculum: on literacy, diversity, and the interplay of children's and teacher's worlds (1993); Social worlds of children learning to write in an urban primary school (1993) and Visions of children as language users: research on language and language education in early childhood (1991).

June 30,2020

* La entrevista fue formulada y respondida en inglés, y la traducción estuvo a cargo de las entrevistadoras, quienes trabajan en la Universidad Nacional de Río Negro, Centro de Estudios del Lenguaje, la Literatura, su Aprendizaje y su Enseñanza, Argentina. Correos electrónicos: ahdyson@illinois.edu, aatorresi@unrn.edu.ar y leisner@unrn.edu.ar.

Cómo citar: Dyson, A. H. (2021). La escritura infantil está entramada con el dibujo, el habla, el canto y el juego / Entrevista por Ana Atorresi y Laura Eisner. Enunciación, 26, 178-185. DOI: https://doi.org/10.14483/22486798.16912

Invitación: 24 de julio de 2020 
Queridos lectores y lectoras:

Agradezco esta oportunidad de escribir sobre mi investigación, con la guía de tres preguntas de reflexión formuladas por Ana Atorresi y Laura Eisner a modo de entrevista. El estado del mundo nos ha dejado a muchos profundamente consternados: el violento virus; la soledad de muchos, incluida la necesidad de las personas de edad avanzada de estar junto a sus familiares o, simplemente, de alguna compañía humana y, además, las continuas manifestaciones de violencia policial. En momentos como estos, muchos sienten la necesidad de proteger la promesa que significan nuestros niños, a la vez que se sienten movilizados por esa misma promesa. Para mí, esta se concreta cuando los niños, como agentes activos, usan la herramienta simbólica de la escritura para representar sus mundos, comunicarse en ellos e, incluso, transformarlos.

Para estudiar la escritura infantil, he observado cómo se desarrolla en la vida en común de los niños, es decir, en el interior de las culturas infantiles. La principal pregunta de investigación que me ha impulsado es: ¿Qué relevancia tiene la escritura para los niños, en cuanto niños y no solo como futuros adultos? Para aprender un sistema simbólico, debe existir una intención de representar y comunicar; los niños, como agentes sociales, aprenden a manipular los elementos de un sistema simbólico para actuar en el mundo (Werner y Kaplan, 1963; Dyson, 1991; Yuan y Uttal, 2017). Entonces, aprender a escribir no es solo aprender el alfabeto y los sonidos de las letras. Se trata de tener un propósito y orquestar los propios conocimientos para saber concretar ese propósito mediante la representación de una idea y la comunicación con los demás. ¿Qué tipo de intenciones impulsan a los niños a escribir en cuanto niños?

A continuación, me referiré a esta pregunta de investigación a medida que abordo cada una de las tres inquietudes planteadas por las editoras. He invitado a niños y niñas a que me acompañen, metafóricamente, al escribir esta carta. Como etnógrafa de la infancia y la literacidad, mis aprendizajes provienen de observar cuidadosamente a los niños. Así, al responder a cada pregunta, ilustraré mi respuesta con una o dos historias breves protagonizadas por niños y niñas participantes en diferentes proyectos; cada una está basada en el análisis de muchos eventos observados en el aula. El principal participante es mi amigo Ta'Von. Ahora es un niño textual: su historia existe especialmente en un libro que estoy escribiendo, basado en las observaciones que realicé de él desde que era un niño de 4 años hasta que tuvo casi 8, y estaba terminando el segundo grado.

Ahora paso a las tres preguntas.

\section{Pregunta 1: ¿Cuál es su perspectiva teórica sobre la escritura de los niños en los contextos del hogar y de la escuela, particularmente en relación con sus identidades?}

Hay una cita del gran psicólogo ruso Lev Vygotsky que aborda esta pregunta con una perspectiva teórica sobre la escritura infantil: "Si la lectura y la escritura se usan solo para escribir saludos oficiales al personal o lo que al maestro se le ocurra [...], entonces el ejercicio será puramente mecánico y probablemente aburrirá pronto al niño; su actividad no se manifestará en su escritura y su personalidad naciente no se desarrollará" (1978, p. 117). ¿Cómo se convierte la escritura en una parte relevante, útil, del repertorio simbólico de los niños? Esta pregunta implica que la escritura es una herramienta social, no un mero producto individual.

Tal perspectiva sobre la escritura infantil emerge de una teoría sociocultural del aprendizaje. Como postuló Vygotsky (1978), el aprendizaje no es un asunto individual; sucede cuando los niños se involucran con las personas que los rodean durante las actividades diarias. Como aprendientes, los niños anticipan y participan en estas actividades cotidianas y quienes interactúan con ellos les responden. A través de estos encuentros dialógicos, los niños aprenden y ocupan su lugar en sus mundos sociales, es decir, aprenden y ponen en acto 
sus identidades. Escribir, entonces, puede ser una afirmación del yo.

Dado que la escritura es una actividad cultural, su uso varía entre las familias y las comunidades, pero existen algunos usos comunes, como hacer listas, ayudar a la memoria con recordatorios en notas autoadhesivas; informar la propiedad de prendas de vestir mediante etiquetas; contactarse con otros a través de tarjetas amistosas, carteles de enojo ("NO TOCAR"), y mensajes que viajan a través del ciberespacio. Y, por supuesto, los autores escriben historias que nos encantan o poesías que recitamos.

Por tanto, aprender a escribir implica aprender a interactuar con otros en situaciones sociales específicas $y$, al mismo tiempo, aprender a manejarse dentro de las ideologías dominantes o las "verdades" sobre las relaciones humanas. Es decir, los niños aprenden qué palabras están disponibles en ciertas situaciones para un chico o para una chica; para una persona de determinada etnia, clase, religión, y así sucesivamente. Como sugiere la teoría dialógica de Bakhtin (1981, 1986), como escritores y hablantes nos movemos en el espacio sociocultural, con diferentes aspectos de nuestra identidad puestos en primer plano o silenciados.

Consideremos, por ejemplo, a Tina, una estudiante de segundo grado en un aula en la que los alumnos podían elegir entre leer sus composiciones en clase o hacer que sus compañeros las representaran. A Tina le encantaba actuar en las historias de los varones, que a menudo trataban sobre X-Men, un grupo de superhéroes de cómic que son humanos mutantes. Los varones le negaban a Tina un papel en sus historias; si incluían a una chica en el equipo de X-Men, no sería una mujer de color. Tina, niña afrodescendiente, se sentía molesta porque los varones no la dejaban jugar.

Entonces, Tina escribió su propia historia de X-Men, con mujeres X-Men, interpretadas por actrices afrodescendientes. Estas X-Men no solo luchaban, sino que celebraban funerales para las camaradas caídas y lloraban y cantaban en esos funerales, lo que fue objetado también por varios chicos. Tina era una activista; quebró el orden masculino y la dominación racial para reclamar su derecho a contar y dirigir historias de superseres maravillosos. (La historia completa se encuentra en Dyson, 1997).

Si observáramos a Tina -o a casi todos los niños durante la primera infancia-, escribir intencionalmente, podríamos notar que la niña no se limitaba simplemente a escribir. La escritura infantil está entramada con el dibujo, el habla, el canto y el juego. (En la clase de Tina, el juego social era el sentido principal de la escritura). Para comprender este entretejido de símbolos, es necesario complejizar la noción de desarrollo de la escritura de Vygotsky (1978). Presento a continuación esta última complejización teórica.

En la etapa de la primera infancia, hay un amplio desarrollo del repertorio simbólico de los niños. El juego es un tipo muy temprano de "escritura", planteaba Vygotsky. Imaginemos a un niño y una niña que quieren jugar a los superhéroes. Adoptan la pose correspondiente y luego uno de ellos toma dos toallas del baño. "Estas son nuestras capas", dice. Y, siguiendo esas palabras transformadoras, las acciones de los niños, junto con las capas y toda la charla que las acompaña, metafóricamente escriben una historia de superhéroes. Ahora imaginemos a esos niños un poco mayores sentados a una mesa con crayones y papel. "Este soy yo -dice él-, y soy un superhéroe. Aquí está mi capa", y las líneas sobre la página se transforman a medida que la historia de los superhéroes encuentra un nuevo medio. La siguiente tarea, dice Vygotsky, es darse cuenta de que pueden dibujarse no solo imágenes, sino también palabras o, diría yo, pueden dibujarse voces.

Sin embargo, no existe una línea lineal; los niños usan su repertorio simbólico (por ejemplo, sus dibujos, sus juegos y su conversación) para apoyar, potenciar o incluso reemplazar la escritura. Consideremos una última historia. Ta'Von, que acababa de cumplir 5 años, se había trasladado de un prejardín de infantes interracial a una escuela y aula 
que le asignaron, en un jardín de mayoría blanca ${ }^{1}$. Ahora, claramente formaba parte de una minoría y, dado que los niños blancos vivían en un vecindario principalmente blanco, $\mathrm{Ta}^{\prime} \mathrm{V}$ on, este pequeño niño afrodescendiente, pasó a enfrentar muchos desafíos que lo construían como "diferente".

Por ejemplo, Ta'Von tenía rastas, un peinado común entre los niños afrodescendientes $-y$ sus padres- en su prejardín. En el jardín de infantes, sus nuevos compañeros lo acusaron de tener "cabello de niña". La raza y el género se articularon para excluirlo del círculo de pertenencia. Sin embargo, Ta'Von ya había descubierto el poder que tenía la composición, a través del dibujo y la escritura, en esta escuela. Hasta entonces, el dibujo de personas de Ta'Von había consistido principalmente en círculos con líneas dispuestas hacia afuera como apéndices. Pero, después de este evento, se dibujó a sí mismo con trenzas claramente distinguibles. "Yo soy negro", les dijo a sus compañeros de banco.

En la diferencia que se había construido en el aula, Ta'Von usó la autoridad de la escritura -en este caso, el dibujo-, para afirmar su yo. Esta definición adquirió dimensiones sociales dada la naturaleza de la institución y la cultura infantil en la que él estaba negociando su forma de abrirse camino en la escuela. Con el tiempo, Ta'Von comenzó a agregar rótulos a sus dibujos; luego, a escribir mensajes ilustrados para sus compañeros, y finalmente, a involucrarse con pares en juegos dramáticos utilizando todo su repertorio simbólico, incluyendo su comprensión emergente del sistema de escritura. (Para el caso completo de Ta' $\mathrm{Von}$, ver Dyson, 2018 y un libro de próxima aparición).

Dado que el neoliberalismo ha promovido la evaluación de capacidades individuales como parte de la rendición de cuentas de las escuelas,

1 Nota de trad.: en Estados Unidos, los niños pueden asistir a un nivel educativo Ilamado preeschool entre los 3 y los 5 años. A los 5, ingresan al kindergarden, cuyo cursado de un año es obligatorio en escuelas públicas o programas privados aprobados por los estados. Aquí hemos traducido preeschool como "prejardín de infantes" y kindergarden como "jardín de infantes", como modo de abarcar las diferentes denominaciones usadas para el (los) nivele(s) anterior(es) al primario en los distintos países de habla hispana. las condiciones requeridas para la escritura intencional han desaparecido. Presentadas solo como habilidades fragmentadas (por ejemplo, colocar signos de puntuación en planillas, realizar pruebas de ortografía y ejercicios de gramática), las tareas de escritura no captan la atención de los niños. Además, las clases que desestiman el juego y, al mismo tiempo, silencian a los niños, son lugares poco fértiles para que la escritura prospere, es decir, para que los niños puedan usar sus relaciones sociales y su repertorio simbólico para hacer de la escritura una herramienta relevante.

Sin embargo, todos los niños y niñas llevan a la escuela sus producciones simbólicas predilectas: hablar, dibujar, jugar, contar historias y algún tipo de experiencia con lo impreso. La capacidad de compartir símbolos y, por tanto, organizar y expresar sentimientos y experiencias es parte de la herencia humana de los niños. Por otra parte, es el momento de representar sus propios dramas, dibujar y escribir sus mundos reales e imaginarios, aportar a los informes escritos sobre investigaciones propuestas en las actividades escolares, escuchar historias y componer las suyas en múltiples medios y tecnologías: estas son las maneras de ayudar a los niños a reconocer que el lenguaje escrito es una herramienta relevante en sus vidas. Quizás, la más importante es un momento de intercambio diario en la clase, en el que los niños puedan compartir sus producciones y los maestros puedan relacionar los textos de los niños con el panorama de los géneros o los propósitos de la escritura previstos para esa jornada.

Todos los niños tienen experiencias e intereses a partir de los cuales es posible desarrollar nuevas habilidades. Pero, bajo la presión política, las instituciones educativas han limitado a los maestros y maestras de tal modo que muchos no se apartan del currículo obligatorio; sus niños son oficialmente reducidos a resultados en exámenes y listas de verificación de habilidades. Sin embargo, lo importante son los niños: ellos están llenos de promesas. 


\section{Pregunta 2: ¿Qué tipo de desafíos metodológicos enfrenta al hacer investigaciones etnográficas con niños pequeños?}

Para comprender cómo la escritura se vuelve relevante para los niños, en cuanto niños, el primer desafío es posicionarse en la clase no como un maestro ni, ciertamente, tampoco como un "espía" del maestro, sino como un adulto amigable y no amenazante, interesado en el punto de vista de los niños. Este no es un papel habitual de los adultos en las aulas. Además, en mis estudios, los niños son principalmente afrodescendientes, ahora 60 años más jóvenes que yo, una mujer blanca mayor. La lectura inicial de los niños sobre mí y mi identidad puede representar desafíos. Pero tengo fe en que el tiempo, la atención y mi sincera curiosidad por lo que está sucediendo finalmente me permitirán ingresar en el mundo social de los niños.

Además, trato de transitar por los vecindarios donde viven los niños, por lo que veo dónde hacen compras, la plaza a la que van y, en general, el ritmo del lugar, con sus paradas de autobús y el tráfico de las personas que caminan por sus aceras. También miro los programas o películas que mencionan los niños, escucho la emisora de radio a la que hacen referencia, descubro a qué guarderías y centros infantiles asisten después del horario escolar. Todo esto hace que sea más fácil seguir la interacción entre los niños.

Cuando comencé mi carrera como investigadora, a finales de la década de 1970, había sido maestra de niños pequeños, y al principio fue difícil no intervenir sobre la marcha cuando surgían confusiones de aprendizaje. Si lo hubiera hecho, habría Ilamado la atención sobre mí misma y, por consiguiente, habría interrumpido la resolución (o la evitación) de problemas por parte de los propios niños. Entonces, mantengo mi posición. Les digo a los niños que estoy ocupada haciendo "mi trabajo": "Yo tengo que tomar nota de lo que está sucediendo". Algunos niños asumen la responsabilidad de ayudarme con mi trabajo, informándome los acontecimientos que creen que debería saber, especialmente si no estuve allí.

En el caso de Ta'Von, desarrollé una relación atípica. Ta'Von no me había prestado mucha atención en el prejardín de infantes. Pero cuando me presenté el primer día de clases en su nueva y desconocida clase, en la que él no conocía a nadie, me saludó con una gran sonrisa, susurrando: "Sabía que vendrías". Yo era, les dijo a los demás, "mi amiga del prejardín". Era cierto, pero yo me mantuve como una amiga discreta y silenciosa.

Además de las cuestiones anteriores en relación con mi posición como investigadora, quiero mencionar otros dos desafíos, aunque son situacionales, es decir, aunque su naturaleza depende de mi propósito de investigación y de la demografía del aula: especialmente, la distribución racial y de género. En primer lugar, aunque la mayoría de las aulas tienen una cultura infantil distintiva, marcada por ciertas prácticas infantiles (por ejemplo, medios de comunicación favoritos, dichos populares, actividades recurrentes e incluso temas de composición comunes), las culturas de los grupos de pares pueden estratificarse en divisiones sociales de raza, clase, religión y género, entre otras. Para ver estas líneas de división, observo quién se asocia con quién en el mundo no oficial, o gobernado por los niños, así como todo patrón social asociado con esas elecciones.

Si mi atención está puesta en entender cómo se sitúa la literacidad en la dinámica de una cultura infantil no oficial estratificada, puedo centrarme en ciertos niños focales que se ubican de manera diferente en la clase. Debido a que esos niños focales interactuarán con otros que se diferencian de ellos, obtendré a través de ellos una idea de la clase en su conjunto. En cambio, en otras ocasiones me concentro solo en un grupo de pares, si mi objetivo es observar a esos niños a través de diversas actividades de literacidad oficiales y no oficiales.

Con $\mathrm{Ta}^{\prime} \bigvee$ Von, me preguntaba cómo ese niño minorizado se abría paso en un aula dominada por niños blancos de clase media. Así, lo seguí a través de prácticas de literacidad oficiales y no oficiales. 
Observé a otros cuando ingresaban en su espacio interactivo. De esta manera, descubrí que, aunque era un aprendiz rápido en el sentido vygotskiano (es decir, respondía fácilmente a la instrucción interactiva) y se aproximó a la escritura con alegría, al comenzar la escuela primaria no tuvo un buen desempeño en los test de alfabetización inicial. Después de todo, no había tenido experiencia con dichos test (a diferencia de algunos de los niños muy entrenados del vecindario), y además había tenido, hasta ese momento, una instrucción limitada en la alfabetización centrada en habilidades aisladas. El desempeño de Ta'Von parecía reforzar los supuestos sobre los Ilamados "niños brillantes" del vecindario en cuanto a que él necesitaba ayuda. El periódico local reflejaba la percepción común de que los niños afrodescendientes no obtienen buenos resultados (de ahí la brecha de desempeño, un supuesto racista, como plantea Kendi [2019]). Ta'Von sufrió limitaciones en sus oportunidades de aprendizaje debido a este estereotipo degradante.

En segundo lugar, además del posicionamiento como investigadora y la sensibilidad a las divisiones sociales establecidas, un último desafío metodológico está representado por los cambios curriculares en la educación infantil en este país [Estados Unidos], incluido el nivel inicial. Como las oportunidades para aprender a través del juego y la conversación han disminuido, como las tareas escolares acotadas se han hecho predominantes, puede ser difícil encontrar en el aula un sitio para estudiar la vida en común de los niños y sus respuestas a la instrucción oficial. Sus conversaciones transcurren como susurros acallados, más allá de mi capacidad auditiva, por no mencionar la de mi grabadora. Sus tareas están tan reguladas que sus intenciones son difíciles de observar, salvo su deseo de terminar la tarea rápidamente. Si no puedo saber nada sobre los niños en estas aulas, tampoco pueden saberlo los maestros. Solo pueden indicar quién obtiene y quién no una tilde de aprobación ante una tarea de habilidades determinada. Esto no funciona.
Pregunta 3: ¿Qué aspectos han cambiado o permanecido igual en el enfoque escolar de la escritura a lo largo de estos años y cuál es la contribución potencial de su investigación al desarrollo de nuevas formas de promover la escritura de los niños en la escuela?

Cuando comencé a trabajar como investigadora, a finales de la década de 1970 y principios de la de 1980, los investigadores de la educación se centraban en la escritura como un proceso individual: Ios niños redactaban, revisaban, editaban y compartían o "publicaban" su trabajo. Pero esto no era lo que yo veía cuando hacía mis observaciones. Veía a los niños hablar, dibujar, jugar y escribir juntos. En ocasiones, miraba el escrito de un niño y, al fijarme en los escritos de aquellos con los que él estaba sentado, veía una coreografía de la escritura, ya que las ideas rebotaban de unos a otros. Los niños escribían (y dibujaban, hablaban y jugaban) con y para los demás; de ahí mi interés temprano y sostenido en la vida social de los niños pequeños como tejedores de símbolos, como personas que usan todo su repertorio simbólico. Mi foco ha estado en el cambio de rol de la escritura -y su alcance- como herramienta funcional. Además, he escrito sobre el poder de un currículum permeable (Dyson, 1993, 2016), en el que las voces e ideas de los niños no solo se comparten con el maestro y con los pares, sino que también se parte de ellas para construir nuevas ideas. La escritura de los niños es importante tanto en los mundos oficiales cuanto en los no oficiales

Con el paso del tiempo, dos tendencias de investigación me han interesado especialmente. Una de ellas se relaciona con las habilidades de escritura que utilizan los niños y las niñas para abordar los problemas en la forma en que los entienden; por ejemplo, habilidades para planificar y solicitar ayuda para adecuar un parque del vecindario al uso de niños y familias. Esta tendencia se enfoca en los niños como ciudadanos activos (por ejemplo, Comber, 2016). La segunda tendencia, ya señalada, 
apunta a cómo los modos de enseñar la escritura definidos por el currículum dirigido a los niños pequeños se han vuelto más estructurados, más orientados a las habilidades puntuales y descontextualizadas, menos abiertos a la diversidad del lenguaje y las experiencias infantiles. Este currículum tiene un profundo impacto en lo que los niños pueden aprender sobre la escritura como un proceso complejo, una herramienta social y un medio simbólico relevante. Esta situación ha afectado mucho mi trabajo; los momentos escolares cotidianos para compartir la escritura infantil han desaparecido y, con ello, también se ha perdido una importante vía para la expresión y conexión infantil.

A medida que cambiaban los contextos de las políticas para la enseñanza de la escritura, fui inclinándome cada vez más hacia proyectos de investigación que no conciben las aulas como unidades aisladas. Más bien, las sitúan en instituciones que son espacios dinámicos atravesados por las divisiones sociales. Los niños que escriben afirman su yo intencionalmente a través del lenguaje que usan, los mundos que imaginan, las experiencias que relatan. Sus oportunidades para desarrollar su escritura en las instituciones dependen de sus relaciones con el maestro o maestra, y con sus compañeros. En consecuencia, en el estudio de Ta' Von, uno de los objetivos fue acercarme a él como escritor en un mundo fracturado, impactado por la raza, la clase y el género. En un mundo así, las escuelas plantean desafíos a los niños, tanto a los privilegiados (cuya comprensión del mundo puede verse limitada por las fronteras de su propio vecindario) como a los no privilegiados, cuyos recursos y energía intelectual deben enfrentar test estáticos y planes de estudios rígidos.

En el mejor de los casos, los maestros observamos y respondemos a cada niño; planificamos actividades que les permiten participar de diferentes maneras con diferentes recursos y que nos permiten observar qué les interesa y, conociendo eso, ampliar su saber y su saber hacer. Los maestros también damos a los niños tiempo para hacer valer sus propias intenciones, para actuar sobre lo que les importa como niños. En aulas como estas, los niños tendrán más posibilidades de apropiarse de la escritura y su repertorio de herramientas para la autoexpresión y la comunicación social. Indagar este proceso ha definido mi vida y me ha dado una enorme alegría.

Con sinceros deseos,

Anne Haas Dyson

Urbana, Illinois, Estados Unidos

\section{Referencias bibliográficas}

Bakhtin, M. (1981). Discourse in the novel. En M. Holquist (ed.), The dialogic imagination: Four essays by M. Bakhtin (pp. 254-422). Trad. C. Emerson y M. Holquist. Austin: University of Texas Press.

Bakhtin, M. (1986). Speech genres and other late essays. Austin: University of Texas Press.

Comber, B. (2016). Literacy, place, and pedagogies of possibility. Nueva York: Routledge.

Dyson, A. H. (1991). The word and the world: Reconceptualizing written language development, or, Do rainbows mean a lot to little girls? Research in the Teaching of English, 25, 97-123. Disponible en https://files.eric.ed.gov/fulltext/ED318010.pdf

Dyson, A. H. (1993). The social worlds of children learning to write in an urban primary school. Nueva York: Teachers College Press.

Dyson, A. H. (1997). Writing superheroes: Contemporary childhood, popular culture, and classroom literacy. Nueva York: Teachers College Press.

Dyson, A. H. (2016). Negotiating a permeable curriculum: Literacy, diversity, and the interplay of teachers' and children's worlds. Ed. por B. Kabuto. Nueva York: Garn Press.

Dyson, A. H. (2018). A sense of belonging: Writing (righting) inclusion and equity in a child's transition to school. Research in the Teaching of English, 52, 236-231. Recuperado de https://library.ncte.org/ journals/RTE/issues/v52-3/29495

Kendi, I. X. (2019). How to be an antiracist. Nueva York: One World. 
Vygotsky, L. S. (1978). Mind in society. Cambridge: Harvard University Press.

Werner, H. y Kaplan, B. (1963). Symbol formation: An organismic developmental approach to language and the expression of thought. Nueva York: John Wiley.
Yuan, L. y Uttal, D. H. (2017). Analogy lays the foundation for two crucial aspects of symbolic development: Intention and correspondence. Topics in Cognitive Science, 9, 738-757. DOI: https://doi. org/10.1111/tops.12273

\section{(c)}

